\title{
The worth of a songbird: ecological economics as a post-normal science
}

\author{
Silvio O. Funtowicz ${ }^{a}$, Jerome R. Ravetz ${ }^{b, *}$ \\ ${ }^{a}$ CEC-Joint Research Centre, Institute for Systems Engineering and Informatics, 1-21020 Ispra (Va), Italy \\ ${ }^{b}$ The Research Methods Consultancy Ltd., Gresham House, 144 High Street, Edgware, Middx HA8 7EZ, UK
}

(Received 21 December 1992; accepted 30 July 1993)

\begin{abstract}
One of the very valuable features of Ecological Economics is its provision for publications under the rubric 'Commentary'. In that way, essays which are not research in the strictest sense can still find proper refereed publication, and can be submitted to the further test of open colleague criticism. This paper is intended to be read in that spirit; and where criticisms are made of the work of particular scholars, that is done because of the significance of their contribution.
\end{abstract}

Key words: Ecological economics; Numeraire; Post-normal science

\section{Introduction}

How much is a songbird worth? Such a question, which might have seemed to belong to academic philosophy only a generation ago, is now the stuff of impassioned politics. For even when we argue for something that is beyond ordinary value, we still seem to find ourselves required to quantify its worth, and to engage in conceptual haggling over a price for its existence. Valuing the songbird thus epitomizes the problems of developing and applying ecological economics as a means to rational and effective decision-making for the environment.

Economics has traditionally been able to maintain its credibility by relegating uncertainties in

\footnotetext{
* Corresponding author.
}

knowledge and complexities in ethics firmly to the sidelines. It has provided puzzles, theoretical and practical, that could be solved within a paradigm that was explicitly modelled on classical physics. In this way, it has been a 'normal' science in the sense articulated by Thomas Kuhn (1962). But when we are confronted by the scientific enigmas and policy riddles of global environmental policies, we can no longer maintain the fiction of a 'normal' economic science. Ecological variables cannot be measured by simple analogy with the cloth fairs of Adam Smith's day. If the valued goods that give richness to our lives are reduced to commodities, then what makes those lives meaningful is itself betrayed.

The new problems of ecological economics call for a 'post-normal science' (Funtowicz and Ravetz, 1991). In this, science is no longer imagined as delivering truth, and it receives a new 
organizing principle, that of quality. This is dynamic, systemic and pragmatic, and therefore requires a new methodology and social organization of work (Funtowicz and Ravetz, 1993). The principle of quality enables us to manage the irreducible uncertainties and ethical complexities that are central to the resolution of issues in post-normal science. It entails the democratization of knowledge by an extension of the peer-community for quality assurance. As the policy process becomes a dialogue, post-normal science encompasses the multiplicity of legitimate perspectives and commitments, and provides new norms of evidence and discourse. The approach of postnormal science enables us to look afresh at the problems of building an ecological economics.

\section{Valuations}

Confronting the paradoxes in setting a monetary value on an irreplaceable songbird forces us to be clear about what is being valued, how it is done, and indeed, what value is. There have been (and doubtless still are) many instances when the cash value of a songbird was quite a straightforward question. There was a time when individual wild songbirds were sought, dead or alive as the case might be, by collectors who provided commodities for quite definite and regular markets. Indeed, part of the rhetorical force of the question of our opening statement is that we all know that it has a new meaning. The concern of ecological economics is not with the provision of saleable specimens, but with the survival of species, or varieties, or of ecosystems. And this new sort of question of worth does not only relate to beautiful things; quite humble, unobtrusive or ugly species (with no market value whatever) may suddenly leap into prominence as some concerned individual or group actively defends them against extinction or displacement as a matter of principle or ethics. For some, things have a value just by existing, independently of markets or even of human civilisation.

The endangered songbird represents a new problem of valuation, one where measurements cannot pretend to be independent of methodol- ogy and ethics. For some, a resource must be capable of valuation in one-dimensional and hence monetary terms in order to be treated in a rational policy debate. They might even argue that providing a market value could lead to greater use of a resource and hence greater benefit. For others, it is near to sacrilege to attach a dollar sign to a species. In the middle are those who feel for this principle, but who reluctantly accept the practical necessity for linear, one-dimensional quantification of all values. Those who strive to preserve this wetland or that interesting species find the onus placed on them to produce a hypothetical monetary value for it, so that it can be put in the scales against the calculable benefits that someone would be able to derive from its exploitation and consequent damage or destruction. Even those who reject monetary quantification in principle will justify it pragmatically in the forensic context when it is the only way to secure compensation for damage that is already done (examples are Bhopal for people, and Exxon Valdez for the natural environment). Any process of valuation seems to be constrained to conform to the convention that money is its natural common language, and therefore appropriate for adoption and use by all stakeholders in any environmental issue.

This is the state of affairs in economics today; but as ecological economics develops, with a coherent vision of a sustainable future, a different conception of value and its measurements will appear. In the first place, monetary price will be seen as a measure of one aspect of value reflecting one particular sort of interest, that which is mainly expressed through the commercial market. To choose any particular operational definition for value involves making a decision about what is important and real; other definitions will reflect the commitments of other stakeholders. Some cultural goods are literally 'priceless', so that a people would rather die than give them up. A new enriched common language, which is not dominated by the worldview of one particular sort of stakeholder (expressed in the monetary standard), would come about when negotiators recognize the irreducible complexity of the issues at stake. This entails a plurality of legitimate 
perspectives and values, including that of the irreplaceable songbird. The issue is not whether it is only the marketplace that can determine value, for economists have long debated other means of valuation; our concern is with the assumption that in any dialogue, all valuations or 'numeraires' should be reducible to a single onedimensional standard.

We could even argue that in the management of the economic system as it actually works, the situation is not so very different. Policies for any national economy are driven to a very significant extent by strategic, political and even ethical considerations. Predictions of the near future in economic affairs are notoriously unreliable, and even explanations of our present states are frequently not much better. Quantitative indicators for the economy, such as money supply, fail to keep up with rapidly changing forms of practice when they are used in regulation. Free trade among nations depends on elaborate structures of regulations and definitions that certify its genuine presence. The arguments based on the virtues of an unregulated market require so many special and artificial assumptions that they belong to the realm of inspirational visions rather than to that of scientific analysis. Hence there is no need to accept the principle of a simple quantification of environmental values and thereby a commodification of environmental goods. Rather, we should start with the awareness that the value of a songbird (new style) not only cannot be, but also should not be, the same sort of thing as the value of a songbird (old style). The forum in which this new sort of value is created and operates is not the 'haggling and niggling' of Adam Smith's marketplace of individual small producers, but the negotiating and mediating of the institutionalized political process. The traditional analytical approach, implicitly or explicitly reducing all goods to commodities, can be recognized as one perspective among several, legitimate as a point of view and as a reflection of real power structures, but not the whole story. The task is to begin the construction of a system of concepts and practices for economics in which all these complementary perspectives can be articulated in a rational dialogue, one in which ethical commit- ments can be articulated. This can be accomplished in an ecological economics which is a post-normal science.

\section{Elements of a post-normal science}

Here we will sketch the elements of a postnormal science which can be used in the development of an ecological economics. These include the scientific management of uncertainty and of quality, the plurality of perspectives and commitments, and the intellectual and social structures that reflect the varied sorts of problem-solving activities.

Many of these elements are already present in the discussion of issues related to ecological economics, thanks to the raising of these issues in popular discourse. Now even those mainstream economists who engage in debate on the environment find themselves adopting the rhetoric of an ecologically sensitive approach. In spite of their efforts to reach orthodox conclusions, their very language reflects how they are forced to recognize and cope with the new problems of economics in an ecological context. In this paper we will make clear and explicit what has already started to happen in an unself-conscious and undisciplined way, by showing how the concepts of post-normal science provide elements for a coherent ecological economics. Our illustration will be a paper by W.D. Nordhaus (1991) on the economics of the greenhouse effect, which was part of an important debate (Dailey et al., 1991). Since the paper displays considerable sophistication in the handling of uncertainties in data, its deeper failings in that regard are particularly instructive.

\subsection{The appropriate management of uncertainty}

First, the manifold uncertainties in ecological problems force economists to adopt a more cautious approach in quantitative arguments than has hitherto been fashionable. Thus the paper by Nordhaus is liberally sprinkled with caveats, including such choice lines as, 'We now move from 
the terra infirma of climate change to the terra incognita of the social and economic impacts of climate change' (p. 930). He devotes the last two of the five points of the conclusion of his paper to a discussion of the various severe uncertainties in his analysis. The recommendation he makes for his model is carefully phrased around its weaknesses: 'Notwithstanding these simplifications, the approach laid out here may help to clarify the questions and help identify the scientific, economic and policy issues that must underpin any rational decision'. There is nothing here about quantitative prediction, or even of policy entailments; 'to clarify the questions' and 'to identify the issues' are suitably modest goals (p. 937).

So far, then, our author exhibits a good understanding of the fact that economics applied to environmental issues does not possess the same degree of control of uncertainties as, say, analytical chemistry. It is not inferior on that account, for economics is the only approach that provides the means for policy decisions. To wait until the relevant high-precision natural sciences were available before doing anything about global warming or species preservation would be a counsel of perfection indistinguishable from a counsel of despair. No empirical science is free from uncertainties; even the basic 'constants' of physics have a history of change, as their 'accepted values' bounce from one point to another, frequently changing by more than the 'error bar' of the previous estimate (Funtowicz and Ravetz, $1990, \mathrm{p} .4)$. The task is to manage the uncertainties that are characteristic of each field so that information of the highest possible quality can be obtained from them.

The management of uncertaintics in the matured quantitative sciences is accomplished by inherited, frequently unself-conscious craft skills. In new fields, particularly those relating to the environment, where the characteristic uncertainties are large, complex, and less well understood, it is necessary to have explicit guidelines for their management. We have provided such guidelines in a system of notations, NUSAP, an acronym for the five categories 'Numeral', 'Unit', 'Spread', 'Assessment' and 'Pedigree'. In this system, every quantity is expressed in terms of these categories which generalize and systematize traditional scientific practice. The first two categories, 'Numeral' and 'Unit', are easily understood; the last three enable the distinction of three sorts of uncertainties. These are at the technical, methodological and epistemological levels, respectively. The first, 'spread', relates to degree of precision, what experimentalists call 'random error', controlled by statistical means. The second, 'assessment', relates to degree of accuracy, or what experimentalists call 'systematic error'. The distinction between the two can be seen from the example of target-shooting. If the shots cluster closely, that is high precision; but for high accuracy they should also be near the bull's-eye. There is another sort of uncertainty, namely (in this analogy) whether there is a target there at all. In the case of mathematical or computer models, all these different uncertainties are well known (although not always skilfully handled); they relate to data, to parameters and to the models themselves and their use. Such 'model uncertainties' reflect deep uncertainty or ignorance; and in the NUSAP system we have a category 'Pedigree' that describes the border with ignorance of the information being expressed (Funtowicz and Ravetz, 1990, chapters 8-10). Our distinction among these three qualitatively different sorts of uncertainty marks the difference between our approach and those which have produced formalisms whereby all uncertainties could be expressed through a single quantitative variable.

All these different sorts of uncertainties can be identified in our example. Most estimates and model outputs in Nordhaus' paper are given as a set of three numbers, or as a central estimate with $a \pm$ for spread; thus the precision of his quantities is well expressed. The accuracy of his estimates is described in various ways; in one crucial place it is conveyed by the descriptive term, 'an informed hunch' (p. 936). This qualifies the spread in the leading estimate (flow of damages to the U.S. economy) from $0.25 \%$ of global output to a possible $2 \%$. The deeper uncertainties are listed in a paragraph of 'important oversimplifications', concluding with a reminder that the analysis 'ignores the issues of uncertainty, in which risk aversion and the possibility of learning 
may modify the stringency and timing of control strategies' (pp. 936-937). This displays the 'border with ignorance' of the analysis quite clearly and explicitly. Thus in his rhetoric at least, the author shows a clear awareness of the presence of the various sorts of uncertainty, and the importance of their being clearly stated.

In spite of this awareness, however, the author does not successfully manage the problems of uncertainty. This is most easily seen in his handling of quantitative information. His crucial Table 6 (reproduced in Table 1 below) has eleven entries of three different sorts. Five entries have numerical values (in billions of dollars) around -1 or -2 , expressed to three significant digits. One entry (impact on farms) is a large interval, [-10.6 to +9.7$]$. And five entries are unquantified, with indicators such as '?' or 'small'. The sum of these eleven entries is given as -6.23 , which seems to be the sum of the five precise terms, added to the average value for the 'farms' entry $(-0.45)$, although that addition done correctly would be -8.55 . The percentage of national income is then calculated to two significant digits, as $-0.26 \%$. If the variability in the dominant term were included in the calculation, this result, the one relevant to policy, would be the interval $[-0.44 \%$ to $+0.4 \%]$. In his discussion, the author says that he 'might raise' the $-0.25 \%$ to $-1 \%$, by an adjustment that is 'purely ad hoc'; and he then gives his 'hunch' that it is less than $-2 \%$. (He tactfully ignores the possibility that his calculation yields an equally likely benefit to the economy). To raise the percentage term to the $2 \%$ limit would require the sum of the non-quantified terms to be greater than the sum of the quantified and averaged terms by a large factor, around 3. All the precision in the quantified terms is then completely lost in the uncertainties in his adjustments factors, where the hunch terms are even bigger than the ad hoc ones.

What then is the point of all the calculations with those entries? The hyper-precision in the expression of the key number $-0.26 \%$, which could equally well be anywhere in the range $\pm 0.5 \%$, shows that this is one of those 'magic numbers' designed to produce confidence in the existence of a hard core of objective fact deep
Table 1

Impact estimates for different sectors, for doubling of $\mathrm{CO}_{2}$, U.S. (positive number indicates gain; negative number loss) (Nordhaus, 1991, Table 6, p. 932)

\begin{tabular}{|c|c|}
\hline Sectors & Billions (1981 \$) \\
\hline \multicolumn{2}{|l|}{ Severely impacted sectors } \\
\hline \multicolumn{2}{|l|}{ Farms } \\
\hline $\begin{array}{l}\text { Impact of greenhouse warming and } \mathrm{CO}_{2} \\
\text { fertilisation }\end{array}$ & -10.6 to +9.7 \\
\hline Forestry, fisheries, other & Small + or - \\
\hline \multicolumn{2}{|l|}{ Moderately impacted sectors } \\
\hline Construction & + \\
\hline Water transportation & $?$ \\
\hline \multicolumn{2}{|l|}{ Energy and utilities } \\
\hline \multicolumn{2}{|l|}{ Energy (electric, gas, oil) } \\
\hline Energy demand & -1.65 \\
\hline Non-electric space heating & 1.16 \\
\hline Water and sanitary & $\dot{-} ?$ \\
\hline \multicolumn{2}{|l|}{ Real estate } \\
\hline \multicolumn{2}{|l|}{ Land-rent component } \\
\hline \multicolumn{2}{|l|}{ Estimate of damage from sca-lcvel risc } \\
\hline Loss of land & -1.55 \\
\hline Protection of sheltered areas & -0.90 \\
\hline Protection of open coasts & -2.84 \\
\hline Hotels, lodging, recreation & $?$ \\
\hline \multicolumn{2}{|l|}{ Totul } \\
\hline \multicolumn{2}{|l|}{ Central estimate } \\
\hline Billions, 1981 level of national income & -6.23 \\
\hline Percentage of national income & -0.26 \\
\hline
\end{tabular}

Sources for Table 6: Underlying data on impacts are summarised in EPA (1988). Translation into national-income accounts by author. Details are available on request.

inside the mass of intuitive fuzz. By the time that the author has admitted the manifold oversimplifications and uncertainties in his analysis, and has shown how strong are the ad hoc adjustments and hunches which are needed to bring his numbers back into the realm of plausibility, we might ask whether the statistical exercises are totally redundant except for rhetorical purposes. The defect of hyper-precision (however much masked by apologies and disclaimers) is not peculiar to the paper under discussion. All too few economists of whatever persuasion know of the maxim of the great mathematician Gauss, 'Lack of mathematical culture is revealed nowhere so conspicuously as in meaningless precision in numerical calculation' (Ravetz, 1971). 
Gauss's principle can be illustrated by an old joke which reveals such meaninglessness in a very telling way (Funtowicz and Ravetz, 1990, p. 44). It is about a museum attendant, who was heard telling visitors that some fossil dinosaur bones were 56000012 years old. When asked how he knew so precisely, he explained that when he came on the job 12 years previously, he was told that they were 56000000 years old then. No one at school told him that sometimes one does not add all the digits; indeed who is told that at school? So we learn informally to avoid the 'fossils joke fallacy' by the use of a 'ballpark arithmetic', in which big uncertainties are allowed to swamp small numbers. But our use of this method is far from perfect, and it can be ignored when convenient. In the case of Nordhaus' analysis, the 'fossils joke fallacy' is concealed under a mass of sophistication about uncertainties and hunches; but a glance at his Table 6 will show that it is there in full strength.

Policy makers are quite familiar with uncertainties of many sorts; but scientific inputs, being 'facts', have traditionally been considered unquestionable. Now that policy debates will include issues of uncertainty and methodology, it is all the more important for ecological economics to possess disciplined techniques for the management of uncertainty. Only then will it be possible for value-commitments to be disentangled from factual assertions. On the basis of our experience, we believe that the techniques and insights of the NUSAP system enable uncertainties to be managed for the achievement of the best possible quality of information; this has been done in a sample case of wetlands evaluation (Costanza et al., 1992). Also, the equally important task of criticizing information offered in a discussion of ecological economics, and evaluating its quality as a basis for policy recommendations, is facilitated by the NUSAP approach.

\subsection{The appropriate management of quality}

Our illustrative example shows inappropriate management of the quality of information in relation both to its inherent uncertainties and to its function as the basis for policy recommendations.
Uncertainty in input information produces irreducible uncertainty in conclusions; the relevant question of quality is the degree to which the recommended policy choices are robust against those underlying uncertainties. To have more certainty in the recommendations than in the arguments on which they are supposedly based, would be very bad methodology indeed.

Looking at the conclusions in our example, we see: 'Climate change is likely to produce a combination of gains and losses with no strong presumption of substantial net economic damage' ( $p$. 933). The following recommendation is vague in language, but quite definite in its prescription: 'a careful weighing of costs and damages will be necessary if a sensible strategy is to be devised' (p. 937). The clear implication of this well-crafted prose is that accuracy in this process of 'careful weighing' is achievable. Hence the burden of proof is now upon those who would impose the unquantified substantial costs on the economy for the sake of avoiding damages from climate change. This heavy prose is in noticeable contrast with the modest claim that the analysis might 'help clarify the questions...' (p. 933). There has been a marked increase in certainty in the move from conclusion to recommendation; where does it come from?

In relation to the input information, the author might well respond that he has shown how the quantifiable part of the effects leads to a very small negative impact indeed; and so it is only reasonable that the non-quantifiable effects should be taken as not very much larger. But his recommendations, however cautiously stated, are clearly quite sensitive to his numerical conclusions; a final figure of $10 \%$ rather than $2 \%$ would lead to a very different emphasis for policy. And the lower figure is itself obtained by an admittedly simplified argument which in the end depends more on the author's economic doctrine (rhetorically defended by his knowledge of pitfalls and anticipation of criticisms) than on his input data and calculations.

We notice that his conclusion of 'no strong presumption of substantial economic impact' is justified entirely by his hunches. Why his hunch leads to an increase by a mere factor of 2 rather 
than 10 , is never discussed. Also, since the hunches are buried in a mass of hyper-precise arithmetical data, assisted by models involving advanced calculus, they are effectively concealed. The argument is thereby provided with an image of quantitative science rather than of doctrine reinforced by guesswork. The criticism of such a methodology is not that we always need high-precision in our economic analyses. Rather, that it is wrong to manipulate the uncertainties in information and conclusions in such a way that recommendations turn out to be far more certain than could possibly be justified scientifically.

The argument in this example not merely conceals its management of quantitative uncertainty; in addition the value-commitments are kept from sight. They are implicit in the leap from the tentative model conclusions to the firm policy recommendations. But the value-commitments, the differential weighting of the various sorts of risks and bencfits, are easily discerned in his practical recommendations. These include 'climatic engineering', with such examples as 'Shoot particles into the stratosphere', or 'Fertilize the ocean with trace iron' (p. 928). The use of the term 'engineering' to describe such vast perturbations with totally unknowable consequences is itself significant; equally so is the claim that 'a number of cost(sic)-effective ones have already been identified' (p. 928).

Being a post-normal science, ecological economics should recognize the presence, importance and legitimacy of such value-commitments for the appropriate management of uncertainty. It should not claim ethical neutrality, nor an indifference to the policy consequences of its arguments. But its discourse should be explicit about the placing of burden of proof, and the adoption of any particular precautionary principle. When these are smuggled into an argument we say that its quality has been sacrificed in the service of the interest of one particular stakeholder in an issue. Forensic advocacy and scientific research are legitimate discourses, each with its place in post-normal science. Having different goals, they employ different methodologies for the management of evidence, uncertainty and contrariety. What is illegitimate is the pretense of using one discourse when actually employing the other, so that the prestige of objective research is used to buttress an advocacy argument. With its hyper-precision of numerical data, specious sophistication about uncertainties, unsupported hunches and loaded rhetoric, this is what is done in the paper we are analyzing.

Up to now, debates on environmental policies have shown a rather crude manipulation of burden of proof; each side stresses the dangers that would result if the position of the opponent is wrong and their policies are adopted nevertheless. Of course, burden of proof is not a familiar concept among researchers who tend to believe that it only applies in the law courts. As it happens, a closely related concept is used in statistical practice with tests designed around the relative importance of the errors of types 1 and 2, or 'false positives' and 'false negatives', that is, 'making something out of nothing' or 'making nothing out of something'. Economists will recognize these as analogous to the 'error costs' of the various sorts of decisions. But as uncertainties become incorporated into ecological economics, the management of burden of proof in a disciplined and standardized way would be possible (Costanza and Cornwell, 1992). This would also benefit the implementation of 'the precautionary principle', now becoming ever more popular, but whose naive interpretation would entail a halt to all innovation, even that intended to benefit the environment. For to require that every proposed innovation be proved harmless would amount to a uniform ban; the task is to articulate varieties of 'burden of proof' that are each appropriate to the issue and the forum of discussion.

The above discussion shows how low-quality arguments can occur when there is confusion about the nature of the discourse in a particular context. It also illustrates how judgements of quality can be made on technical arguments independently of a technical analysis of the subjectmatter. The nature of policy debates involving science has been transformed by the success of non-expert stakeholders in contributing to the assessment of quality. Previously, only subjectspecialty peers could assess quality in connection with refereeing or peer-review. But when science 
became used in policy, it was discovered that laypersons (e.g. judges, journalists, scientists from another field, or just citizens) could master enough of the methodology to become effective participants in the dialogue.

A basic principle of post-normal science is that these new participants are indispensable. This extension of the peer community is essential for maintaining the quality of the process of resolution of complex issues. Thus the appropriate management of quality is enriched to include this multiplicity of participants and perspectives. For this extended peer community, appropriate sorts of discourse, norms and institutional arrangements will need to be developed. The key organizing principle will be quality, in relation to the requirements of the dialogue, rather than abstract truth. The criteria of quality in this new context will, as in traditional science, presuppose ethical principles. But in this case, the principles will be explicit and will become part of the dialogue.

\subsection{Plurality of commitments and perspectives}

Quality, explicitly comprising ethics and morality, thus becomes the organizing principle of post-normal science because the old ideal of scientific truth is no longer attainable or relevant for policy. Since no particular expertise can deliver certainty for policy decisions, no expertise can claim a monopoly of wisdom or competence for its special perspective. The emerging shape of dialogue on the great issues is based on the recognition of a plurality of legitimate perspectives, each with its special power-bases, commitments and insights. Different constituencies, such as consumers, NIMBYs, and representatives of the disadvantaged, along with champions of one or another aspect of the natural environment, have a legitimate place at the negotiating table together with the spokespersons for industries and governments, and the certified experts in economics or other relevant disciplines. The dialogue among them should be modelled on principled advocacy rather than on the pretense of uncommitted scholarship. Its goal should not be to establish which single voice is 'right', inevitably making the others 'wrong'. Rather, the policy issues at stake are to be negotiated and mediated; and in this process both the research and advocacy modes of argument will have their place. An honest recognition of conflicting interests and of power relationships will protect such negotiations from becoming a covert co-optation by one side.

An ecological economics that is involved in this sort of process will have a new form. We call it 'post-normal' as a reminder of the contrast with the 'puzzle-solving within a (dogmatic) paradigm' of the 'normal science' articulated by Thomas Kuhn. The inherent and necessary multiplicity of perspectives on any issue requires a pluralism of methodologies, even within the scientific components. Any environmental issue comprises scientific inputs and policy consequences involving a number of disciplines, along with all the social and ethical considerations. Resolving such issues cannot be accomplished even by calls for 'multi-disciplinary' research, for in that there is a tendency for each specialist to play safe, and to disclaim competence and therefore responsibility for assessing the quality of the contributions of others. In the context of traditional normal science, this practice could be tolerated so long as subject-specialties could maintain their own assurance of quality; but in postnormal science, it cannot be afforded.

This plurality of perspectives and commitments does not deny the special competence of people with special expertise; nor does it mean anything like the importation of some token laypersons onto a review committee. However, it does mean that there is a mixing and blending of skills, partly technical and partly personal, so that all those engaged on an issue can enrich the comprehension of the whole. There is no sharp line dividing the 'expert' constituency from the 'lay', particularly since each expert will be 'lay' with respect to at least some of the others. Under such circumstances, which will hold for the study and practice of ecological economics, the idea of a 'paradigm' which defines a field of puzzle-solving practice is easily seen to be inappropriate. The guiding principle in the dialogue on an issue in post-normal science is quality rather than truth; and it is operationalized through this plurality of 
competencies, perspectives and commitments. We cannot convey what the post-normal science of ecological economics is about if we retain a picture of the process that depends on the expectation either of definitive scientific knowledge or of enforced uniformity of opinions.

\subsection{Intellectual structures}

All previous models of 'science' correspond to the ideal of curiosity-motivated research, aiming exclusively at 'public knowledge'. In such a framework it is reasonable to attempt to define 'foundations' to serve as a basis for unity among researchers in the field and also as an organizing principle for advanced teaching. In mission-oriented research, however, such an attempt is irrelevant, as the organizing principle is the production of 'corporate know-how', and for each particular project temporary teams are assembled comprising the relevant skills. Thus much if not most scientific research is now independent of traditional field-boundaries and of conceptual foundations.

In the issue-driven research of post-normal science, the search for 'foundations' can be the source of real confusion since it distracts attention from the real tasks of building a community. The unity in post-normal science derives not primarily from a shared knowledge base, but from a common commitment to certain sorts of approaches for resolving complex policy issues. For post-normal science, knowledge divided into closed subject-specialties is as unthinkable as knowledge divided among closed corporate owners. The sharp divisions of social roles among the various sorts of research, and the even sharper traditional division between research and advocacy, are antithetical to what post-normal science is about. Similarly, suppression of issues of ethics or of power in the interests of tidy scientific puzzle-solving or of a superficial consensus violate the spirit of post-normal science. Commitment to the resolution of an issue will take people through any of the forms of problem-solving activity and dialogue that are appropriate for them. This fluidity might seem to threaten the integrity of the intellectual structures that inform the work, along the lines of the 'permanent revolution' in science advocated in the 1960s and 1970s. But that would be to miss the point of how quality assurance operates in post-normal science, and of the essential role of its ethical basis.

Of course, there is an ethical component in curiosity-motivated and mission-oriented research; in the absence of ethical commitment of a particular sort, the whole process of quality assurance would collapse (Ravetz, 1971). But this commitment can be of a very constricted, rarefied and safe sort, where morality concerns only the process and the product, and not its use or abuse, nor the social relations of its production. This traditional attitude has led to scientists claiming credit for the all beneficial consequences of research, while blaming society for any harm. Postnormal science provides no such moral shelter; while the traditional ethical concerns for internal quality must be maintained, engagement on policy issues brings one into politics where the game may become very rough indeed. But through an explicit awareness of the problems of quality assurance, and a common ethical commitment to the resolution of issues, the participants can indeed maintain quality in post-normal science.

\subsection{Social structures}

The contemporary scientific system recognizes the contributions of various sorts of research, including the curiosity-motivated along with the mission-oriented, the latter conducted in bureaucratic institutions. These missions may derive from environmental issues, as well as from opportunities in biomedicine or the requirements of industry or defense. But the researchers are employees whose work is directed and constrained by managers; and it is these who will decide priorities on the basis of the institutional mission rather than on the publicly defined issues. The product of the researchers' work is not 'public knowledge', for in general the public has no legal right to see it. By contrast the activity of 'research' in issue-driven post-normal science may well include investigative journalism and related techniques as the only way to bring such corporately owned knowledge into public discussion. 
Curiosity-motivated and mission-oriented research have complementary properties; the former produces public knowledge but within rigid disciplinary boxes; the latter is transdisciplinary, but bureaucratized and private. The issue-driven research of post-normal science must combine the positive features of these other forms, and develop appropriate institutional arrangements or structures to achieve this. These frameworks are likely to be fluid, like the distinctions of types of research within post-normal science. Otherwise the opposed dangers of closure or fragmentation will be difficult to keep in check.

Of course, ecological cconomics will need its complement of well-defined research problems which might be of the curiosity-motivated sort. Some of these will be empirical, but there can others of a more theoretical cast, perhaps using the enriched conception of quantity that is appropriate for the context. For example, the practice of valuing a lost life is legitimate in the context of compensation post hoc, but (as the Ford Pinto affair showed) it is fraught both morally and legally if done ante hoc in a design and costing exercise. Bare numbers cannot express the distinction between ethical and unethical quantifications, and techniques for this important function will need to be developed and adopted. Such research would necessarily span the range from the mathematical sciences to ethics, and also that from theory to broad diffusion.

Parallel to this, at the other end of the process, the tasks of quality assurance in the resolution of policy issues will require special institutional arrangements and methods (Funtowicz and Ravetz, 1992). There is some experience of such processes in NIMBY politics, mainly in America, where negotiation and mediation play an important role. The plurality of stakeholders with their own perspectives and commitments will produce a different sort of dialogue from that in either curiosity-motivated or mission-oriented research. Here the opposed dangers are co-optation and anarchy; the democratization of expertise in this case requires a clear understanding of its inherent tensions, and the education of all participants about the process.

\section{Conclusion}

If we care about songbirds as well as other symbols of environmental value, resources will need to be devoted to their protection and choices will need to be made; that is the contribution of the perspective of cconomics. But the issue is not simply one of allocation. The worth of a songbird definitely has its monetary aspect; but the endangered songbird is not thereby reduced to a commodity, any more than any other exemplification of love. And as the rise of ecological economics has shown, the songbird's worth also lies in its teaching us about ourselves and what we want to do with our lives while we are here. With the provision of intellectual tools for the management of that enriched task of policy making, involving scientific uncertainties and value commitments at its core, ecological economics can establish itself as an effective post-normal science, moving to the centre of the economics discipline in time for the next century.

\section{Acknowledgements}

We are grateful to Faye Duchin, Martin O'Connor and Richard M. Dawson for their contributions to the development of this paper.

\section{References}

Costanza, R. and Cornwell, L., 1992. The 4P approach to dealing with uncertainty. Environment, 34: 12-20, 34.

Costanza, R., Funtowicz, S.O. and Ravetz, J.R., 1992. Assessing and communicating data quality in policy-relevant research. Environ. Manage., 16: 121-131.

Dailey G.C., Ehrlich, P.R., Money, H.A. and Ehrlich, A.H., 1991. Greenhouse economics: learn before you leap. Ecol. Econ., 4: 1-10.

EPA, 1988. The potential effects of global climate change on the United States. Draft Report to Congress. U.S. Environmental Protection Agency, Washington, DC.

Funtowicz, S.O. and Ravetz, J.R., 1990. Uncertainty and Quality in Science for Policy. Kluwer Academic Press, Dordrecht.

Funtowicz, S.O. and Ravetz, J.R., 1991. A new scientific 
methodology for global environmental issues. In: $R$. Costanza (Editor), Ecological Economics: the Science and Management of Sustainability. Columbia University Press, New York.

Funtowicz, S.O. and Ravetz, J.R., 1992. Three types of risk assessment and the emergence of post-normal science. In: D. Golding and S. Krimsky (Editors), Social Theories of Risk. Greenwood Press, New York, NY.
Funtowicz, S.O. and Ravetz, J.R., 1993. Science for the postnormal age. Futures, 25: 735-755.

Kuhn, T.S., 1962. The Structure of Scientific Revolutions. University of Chicago Press, Chicago, IL.

Nordhaus, W.D., 1991. To slow or not to slow: the economics of the greenhouse effect. Econ. J., 101: 920-937.

Ravetz, J.R., 1971. Scientific Knowledge and its Social Problems. Clarendon Press, Oxford. 